\title{
Assessment of adrenal cortical function after death in cases of senile osteoporosis
}

\author{
R. A. CALDWELL ${ }^{1}$ \\ From the Department of Pathology, University of Sheffield
}

SYNOPSIS Adrenal cortical function was assessed after death by indirect methods in an unselected series of 31 cases dying in hospital, and comparison made between cases showing normal bone density and those showing unequivocal senile osteoporosis.

The osteoporotic cases showed evidence of slightly greater cortical activity than did cases with normal bone density but this was considered to be largely due to the greater degree of stress suffered by the osteoporotic cases.

There was no evidence to suggest adrenal involution, or 'adrenopause', in any of the cases, and no changes were present to suggest that the osteoporosis was the result of terminal excess of 'antianabolic' steroids. It is considered that the osteoporosis was more probably due to gonadal sexhormone (oestrogen) deficiency.

The normal production of adrenal corticosteroid in healthy subjects permits many of the essential body functions to proceed (Ingle, 1953) but its abnormal production is in many cases associated with welldefined disease states. In Cushing's syndrome, which is associated with an excessive output of adrenal corticosteroids, principally of the $\mathrm{C}_{21}$ group, osteoporosis is a common feature, and because the mainly spinal distribution of this type of osteoporosis is similar to senile osteoporosis, Albright (1947) has drawn attention to the possible role of the adrenal glands in the latter condition. He suggested that adrenal involution, which he termed an 'adrenopause', might be responsible.

Relatively few studies of adrenal cortical function in senile osteoporosis have been published, and unfortunately, where accurate chemical assessments of adrenal corticosteroid output have been made during life, e.g., by Urist (1960a), the diagnosis of osteoporosis has usually been made by the notoriously inaccurate clinical radiograph of the spine. Until recently, however, no standard methods have been available to assess accurately the degree of osteoporosis of the spine and pelvis, so that comparison between cases was not possible until Beck and Nordin (1960) described a histological method, employing biopsy of the iliac crest, and Caldwell and Collins (1961) described a combined radio-

'Present address: The Department of Pathology, Princess Alexandra Hospital, Brisbane, Australia.

Received for publication 7 December 1961. graphic and chemical method of assessing the density of lumbar vertebral body slabs obtained in the post-mortem room. During a study of necropsied cases using the latter method, adrenal glands were obtained sufficiently soon after death in a proportion of cases to permit indirect assessment of cortical function. Indirect methods, employing the study of cortical lipoid and ribonucleic acid content, were necessary because, as Carr (1959) has stated, the estimation of corticosteroids in the adrenal veins and enzymatic synthetic power in vitro are not practicable on post-mortem material.

\section{MATERIALS AND METHODS}

Adrenal glands and mid-sagittal vertebral body slabs, $1 \mathrm{~cm}$. in thickness, were examined in a series of 31 necropsied cases at the Sheffield Royal Infirmary, which were selected only because the adrenal glands could be obtained soon enough after death and were free from metastatic tumour.

BONE DENSITY ASSESSMENT Caldwell and Collins (1961) have shown that, provided other bone rarefying conditions such as osteomalacia and osteitis fibrosa have been excluded by histological examination, the degree of osteoporosis can be expressed either as calcium per unit volume of bone or as units of radiographic density. Using the former index, which is rather more precise, a figure of about $60 \mathrm{mg}$. of calcium per c.c. of anatomical bone represented the lower limit of normal (unpublished observations). The calcium method was therefore employed in this investigation. 
HISTOLOGICAL PROCEDURes Both adrenal glands were obtained from each case within six hours of death, dissected free from fat, and weighed.

After fixing the glands in neutral $10 \%$ formalin, frozen sections were cut at $12 \mu$ and stained with oil red $4 \mathrm{~B}$ and haematoxylin to demonstrate cortical lipoids. Cortical ribonucleic acid was demonstrated by staining paraffinembedded sections cut at $5 \mu$ with pyronin methyl green as described by Brachet (1953). Ribonucleic acid is shown as pink granules in the cell cytoplasm, but to ensure specificity two control sections were also employed in each case. One of these was treated before staining with a solution of crystalline ribonuclease (Kunitz) containing $0.1 \mathrm{mg}$. of enzyme per $\mathrm{ml}$. of distilled water at $p \mathrm{H} 6.0$ for one hour at $37^{\circ} \mathrm{C}$. The second was treated with distilled water alone for a similar period. Failure of the granules to stain in the ribonuclease-treated sections indicated specificity. Haematoxylin-and-eosin-stained sections of adrenal glands and also of third lumbar vertebral bodies were examined to exclude causes of bone rarefaction other than pure uncomplicated osteoporosis.

\section{RESULTS}

The results of the examinations of the adrenal glands and lumbar vertebral slabs in 31 necropsied cases (19 male and 12 female) are presented here and illustrated.

The total gland weights, histochemical patterns, and the density of the fourth lumbar vertebral slabs, expressed as $\mathrm{mg}$. of calcium per c.c. of anatomical bone, are shown for all cases in Table I.

The gland cortical contents of lipoid (Figs. 1, 2, and 3) and of ribonucleic acid (Figs. 4, 5, and 6) were assessed visually from microscopy of the sections and are expressed as a percentage of the possible maximum. Glands from the same case were found to correspond closely. The cortical lipoid results varied from 5 to $90 \%$ and the ribonucleic acid results from 10 to $95 \%$. The results of these two estimations bore an inverse relationship in every case, and agreed so closely that only the results for ribonucleic acid, being the more direct index of activity, are subsequently given.

Bone density results also showed a considerable range and varied from 38 to $106 \mathrm{mg}$. of calcium per c.c. of vertebral body. Eight of the 31 cases (five male and three female) showed vertebral calcium contents of $55 \mathrm{mg}$. per c.c. or less, which is considered to indicate unequivocal osteoporosis. A further eight cases (six male and two female) had $82 \mathrm{mg}$. of calcium per c.c. or more and are therefore considered to have a high normal bone density. For comparison, these results are shown in Tables II and III, together with the condition or conditions leading to death, and the approximate duration of the period of stress, assessed as the duration of the final illness in days.

\section{TABLE I}

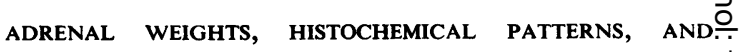
DEGREE OF BONE DENSITY OF FOURTH LUMBAR VERTEBRA IN 31 NECROPSIES

\begin{tabular}{|c|c|c|c|c|c|c|}
\hline $\begin{array}{l}\text { Case } \\
\text { No. }\end{array}$ & $\operatorname{Sex}$ & Age & $\begin{array}{l}\text { Vertebral } \\
\text { Body } \\
\text { Calcium } \\
\text { (mg. per } \\
\text { c.c.) }\end{array}$ & $\begin{array}{l}\text { Adrenal } \\
\text { Weights } \\
\text { (g.) }\end{array}$ & $\begin{array}{l}\text { Cortical } \\
\text { Lipoid } \\
(\%)\end{array}$ & $\begin{array}{l}\text { Cortical } \\
\text { Ribonuclei } \\
\text { Acid } \\
(\%)\end{array}$ \\
\hline 1 & $\mathbf{M}$ & 17 & 87 & $9 \cdot 0$ & 50 & 55 \\
\hline 2 & $\mathbf{F}$ & 70 & 88 & $11 \cdot 0$ & $\begin{array}{l}90 \\
\text { (reversion) }\end{array}$ & 15 \\
\hline 3 & $\mathbf{M}$ & 66 & 59 & $16 \cdot 0$ & $\begin{array}{l}80 \\
\text { (reversion) }\end{array}$ & 10 \\
\hline 4 & $\mathbf{M}$ & 76 & 84 & $10 \cdot 5$ & 25 & 80 \\
\hline 5 & $\mathbf{M}$ & 48 & 81 & $12 \cdot 8$ & $\begin{array}{c}60 \\
\text { (reversion) }\end{array}$ & 50 \\
\hline 6 & $\mathbf{M}$ & 55 & 38 & $15 \cdot 0$ & 75 & 30 \\
\hline 7 & $\mathbf{F}$ & 58 & 84 & $20 \cdot 0$ & 80 & 25 \\
\hline 8 & $\mathbf{M}$ & 52 & 69 & 14.0 & 30 & 80 \\
\hline 9 & $\mathbf{F}$ & 73 & 57 & 11.0 & 75 & 20 \\
\hline 10 & $\mathbf{M}$ & 74 & 66 & 14.0 & 5 & 95 \\
\hline 11 & $\mathbf{M}$ & 83 & 77 & $9 \cdot 0$ & 70 & 40 \\
\hline 12 & $\mathbf{F}$ & 54 & 59 & 13.0 & 75 & 30 \\
\hline 13 & $\mathbf{M}$ & 56 & 76 & $14 \cdot 5$ & 20 & 75 \\
\hline 14 & $\mathbf{M}$ & 59 & 84 & $11 \cdot 0$ & 15 & 85 \\
\hline 15 & $\mathbf{M}$ & 34 & 88 & $16 \cdot 0$ & 60 & 45 \\
\hline 16 & $\mathbf{F}$ & 61 & 72 & $13 \cdot 5$ & 30 & 80 \\
\hline 17 & $\mathbf{F}$ & 59 & 78 & $16 \cdot 5$ & 10 & 90 \\
\hline 18 & $\mathbf{M}$ & 19 & 106 & $15 \cdot 5$ & 25 & 80 \\
\hline 19 & $\mathbf{M}$ & 73 & 82 & $12 \cdot 5$ & 75 & 30 \\
\hline 20 & $\mathbf{M}$ & 60 & 44 & $14 \cdot 5$ & 80 & 30 \\
\hline 21 & $\mathbf{M}$ & 50 & 59 & 13.8 & 80 & 20 \\
\hline 22 & $\mathbf{F}$ & 66 & 60 & 11.0 & 75 & 30 \\
\hline 23 & $\mathbf{F}$ & 81 & 48 & 12.0 & 30 & 80 \\
\hline 24 & $\mathrm{~F}$ & 45 & 67 & $15 \cdot 5$ & 5 & 90 \\
\hline 25 & $\mathbf{F}$ & 67 & 77 & $15 \cdot 5$ & 70 & 40 \\
\hline 26 & $\mathbf{F}$ & 71 & 53 & 10.0 & 20 & 90 \\
\hline 27 & $\mathbf{M}$ & 51 & 81 & $13 \cdot 5$ & 20 & 80 \\
\hline 28 & F & 68 & 55 & $16 \cdot 5$ & 10 & 95 \\
\hline 29 & $\mathbf{M}$ & 76 & 47 & 13.5 & 45 & 60 \\
\hline 30 & $\mathbf{M}$ & 66 & 53 & 20.0 & 5 & 95 \\
\hline 31 & $\mathbf{M}$ & 61 & 47 & 14.5 & 80 & 25 \\
\hline
\end{tabular}

As would be expected in cases of senile osteoporosis the average age of the osteoporotic group (67 years) was greater than that of the control group (50 years) and in the former group the duration of $\mathrm{O}$ the period of stress was also greater. The average gland weight (14.5 g.) and ribonucleic acid content 5 $(63 \%)$ in the osteoporotic group were, however, also greater than the control group's $13.5 \mathrm{~g}$. and $51 \%$. respectively. If one accepts that for cortical ribonu- $N$ cleic acid a figure of about $30 \%$ represents the upper limit of normal (see below) then the result for the control group is also somewhat high, but it must be ${ }^{\omega}$ remembered that even this group is not composed of normal subjects and is merely a less elderly group of non-osteoporotic patients dying in hospital. Two of these cases, however, were normal young adult ${ }^{-}$ males who died accidentally and instantaneously, $\frac{0}{\circ}$ and they showed cortical ribonucleic acid levels of 45 and $55 \%$ respectively.

Routine histological examination of the glands $\stackrel{\mathbb{}}{\circ}$ revealed proportions of compact eosinophilic cells in? the cortices which were in keeping with the results for 


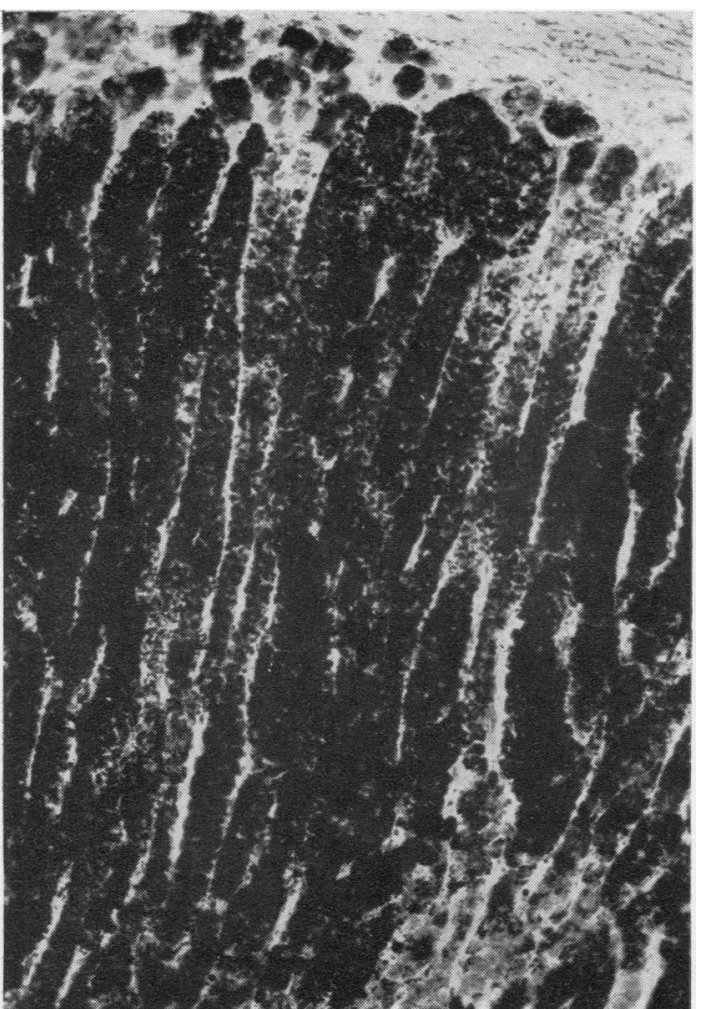

Fis. 1. Adrenal cortex of gland showing $90 \%$ of lipoid. Oil red $4 B$ and haematoxylin $\times 90$.

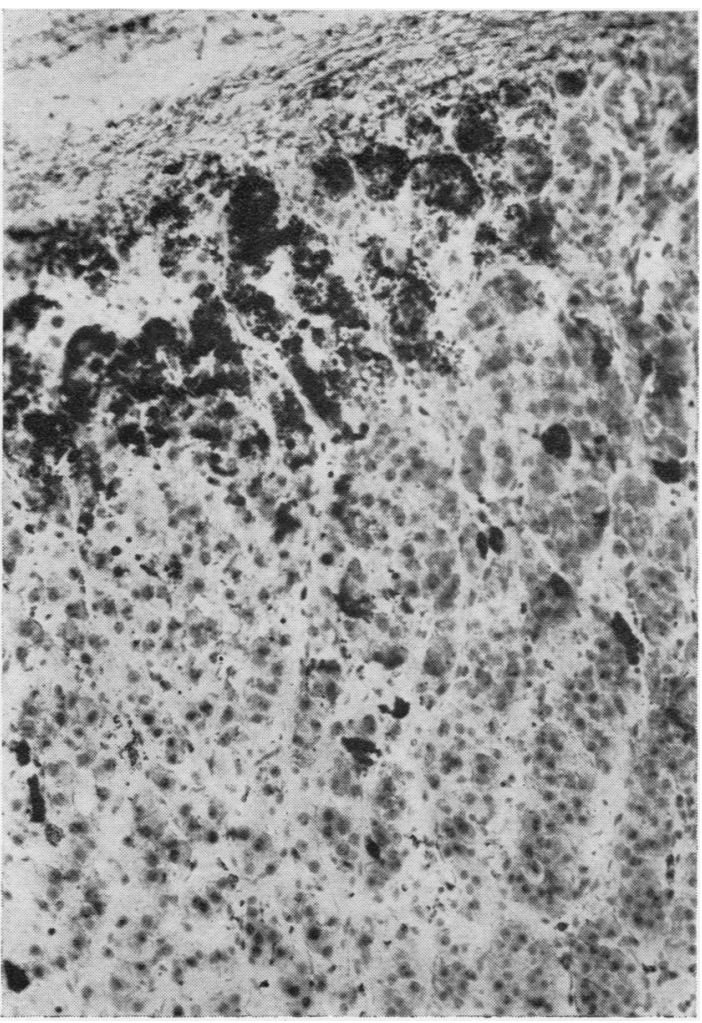

FIG. 2. Adrenal cortex of gland showing $5 \%$ lipoid. Oil red $4 B$ and haematoxylin $\times 90$.

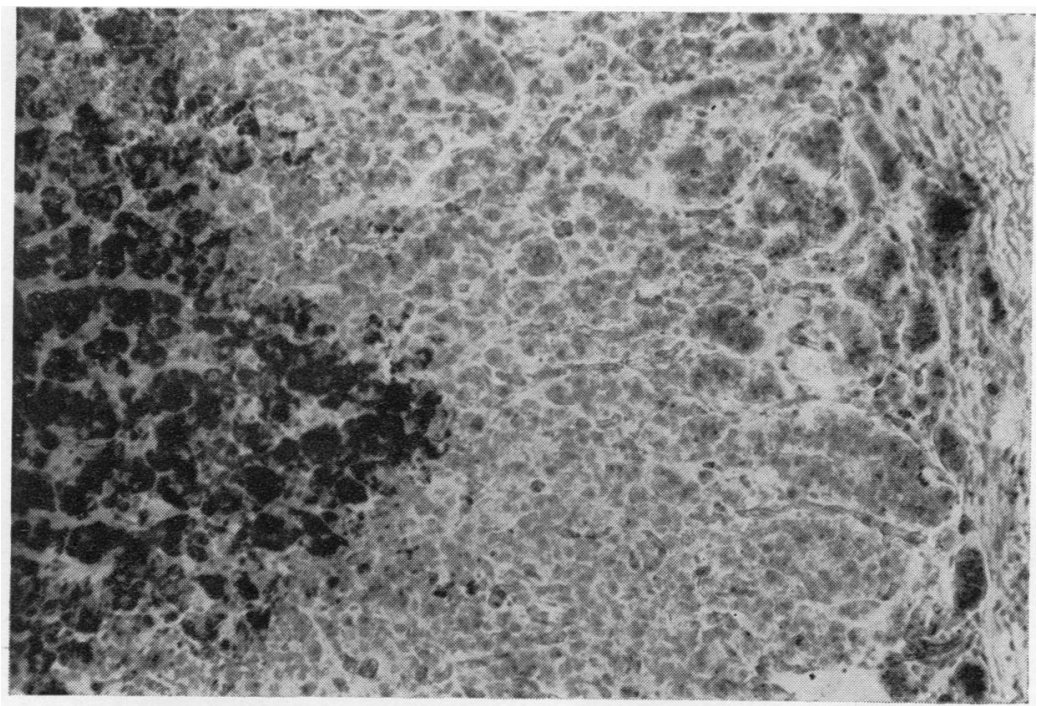

FIG. 3. Adrenal cortex of gland showing lipoid reversion. Lipoid has begun to be restocked in the inner part of the cortex. Oil red $4 B$ and haematoxylin $\times 90$. 


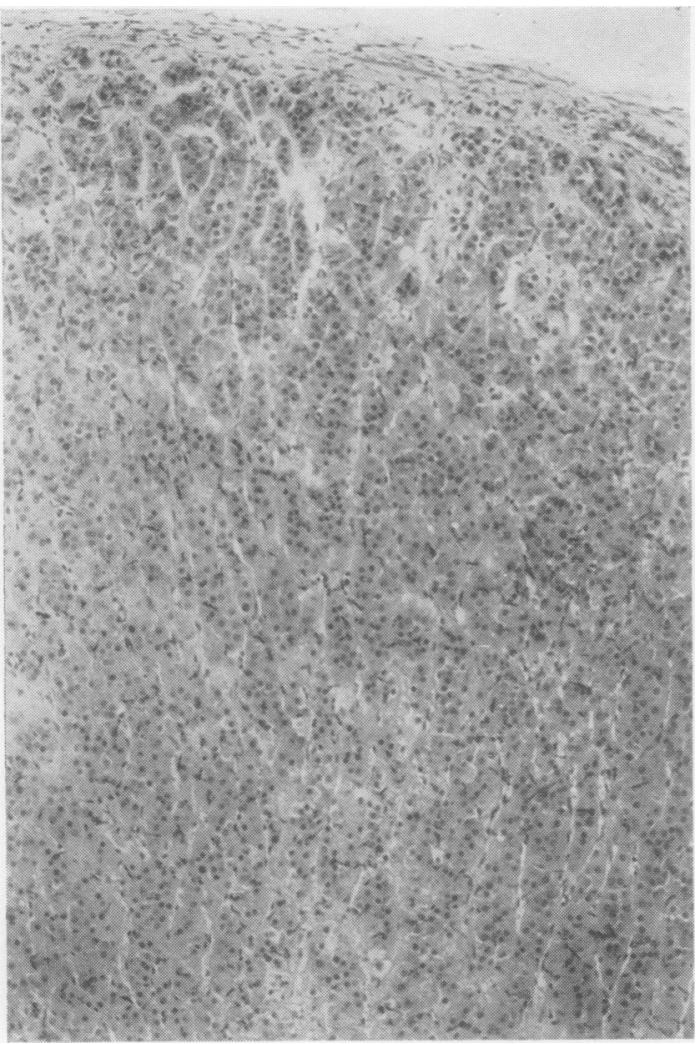

FIG. 4. Adrenal cortex. Compact cells extend right up to the capsule. The total ribonucleic acid content of this gland was $95 \%$. Haematoxylin and eosin $\times 90$.

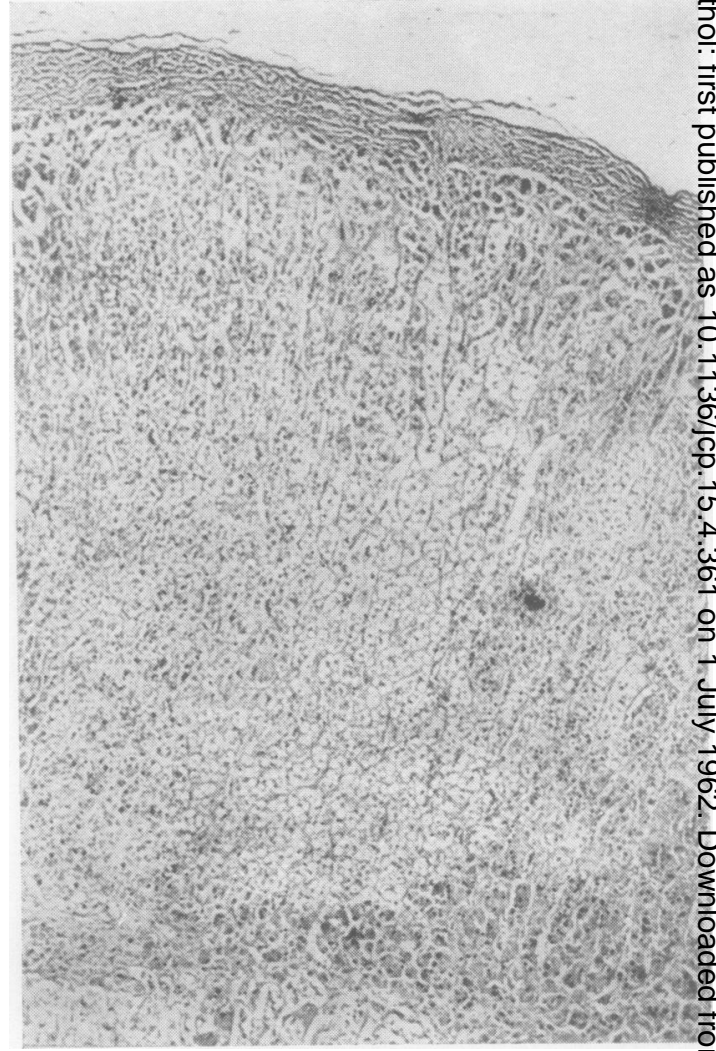

FIG. 5. Adrenal cortex of gland showing $10 \%$ of ribo nucleic acid which is almost entirely localized to the zon reticularis. Pyronin methyl green $>50$.

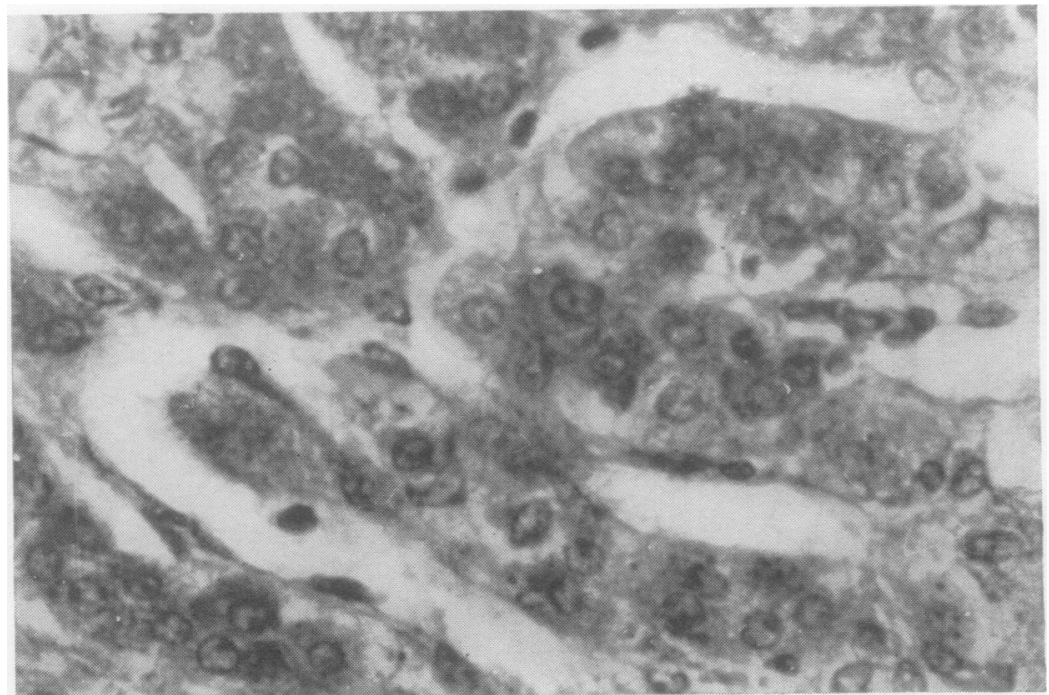

FIG. 6. Adrenal cortex showing detail of cytoplasmic ribonucleic acid granules. Pyronin methyl green $\times 500$. 
TABLE II

ADRENAL WEIGHT AND RIBONUCLEIC ACID CONTENT, CAUSE OF DEATH, AND DURATION OF STRESS IN EIGHT CASES OF VERTEBRAL OSTEOPOROSIS

\begin{tabular}{|c|c|c|c|c|c|c|c|}
\hline $\begin{array}{l}\text { Case } \\
\text { No. }\end{array}$ & Principal Conditions Leading to Death & Age & $\operatorname{Sex}$ & $\begin{array}{l}\text { Duration of } \\
\text { Stress } \\
\text { (days) }\end{array}$ & $\begin{array}{l}\text { Gland } \\
\text { Weight } \\
(\mathrm{g} .)\end{array}$ & $\begin{array}{l}\text { Cortical } \\
\text { Ribonucleic } \\
\text { Acid }(\%)\end{array}$ & $\begin{array}{l}\text { Vertebral } \\
\text { Bone Calcium } \\
\text { (mg. per c.c.) }\end{array}$ \\
\hline 6 & Cor pulmonale & 55 & $\mathbf{M}$ & 4 & $15 \cdot 0$ & 30 & 38 \\
\hline 20 & Coronary thrombosis & 60 & $\mathbf{M}$ & 2 & $14 \cdot 5$ & 30 & 44 \\
\hline 23 & Cholecystitis (operated) & 81 & $\mathbf{F}$ & 17 & $12 \cdot 0$ & 80 & 48 \\
\hline 26 & Portal cirrhosis, oesophageal haemorrhage, & & & & & & \\
\hline & bronchopneumonia & 71 & $\mathbf{F}$ & 29 & $10 \cdot 0$ & 90 & 53 \\
\hline 28 & Carcinoma of rectum (operated), peritonitis & 68 & $\mathbf{F}$ & 22 & $16 \cdot 5$ & 95 & 55 \\
\hline 29 & Uraemia and bronchopneumonia & 76 & $\mathbf{M}$ & 10 & $13 \cdot 5$ & 60 & 47 \\
\hline 30 & Carcinoma of stomach, bronchopneumonia & 66 & $\mathbf{M}$ & 17 & $20 \cdot 0$ & 95 & 53 \\
\hline \multirow[t]{2}{*}{31} & Hypertension, cerebral haemorrhage & 61 & $\mathbf{M}$ & 1 & $14 \cdot 5$ & 25 & 47 \\
\hline & Average & 67 & & & $14 \cdot 5$ & 63 & 48 \\
\hline
\end{tabular}

TABLE III

ADRENAL WEIGHT AND RIBONUCLEIC ACID CONTENT, CAUSE OF DEATH, AND DURATION OF STRESS IN EIGHT CASES WITH HIGH NORMAL VERTEBRAL BONE DENSITY

\begin{tabular}{|c|c|c|c|c|c|c|c|}
\hline $\begin{array}{l}\text { Case } \\
\text { No. }\end{array}$ & Principal Conditions Leading to Death & Age & Sex & $\begin{array}{l}\text { Duration of } \\
\text { Stress } \\
\text { (days) }\end{array}$ & $\begin{array}{l}\text { Gland } \\
\text { Weight } \\
\text { (g.) }\end{array}$ & $\begin{array}{l}\text { Cortical } \\
\text { Ribonucleic } \\
\text { Acid }(\%)\end{array}$ & $\begin{array}{l}\text { Vertebral } \\
\text { Bone Calcium } \\
\text { (mg. per c.c.) }\end{array}$ \\
\hline $\mathbf{L 1}$ & Accidental, instantaneous death & 17 & $\mathbf{M}$ & - & $9 \cdot 0$ & 55 & 87 \\
\hline 2 & Aortic thrombosis, cerebral softening & 70 & $\mathbf{F}$ & 86 & $11 \cdot 0$ & 15 & 88 \\
\hline 4 & Coronary thrombosis & 76 & $\mathbf{M}$ & 1 & $10 \cdot 5$ & 80 & 84 \\
\hline 7 & Malignant cerebral tumour & 58 & $\mathbf{F}$ & 3 & $20 \cdot 0$ & 25 & 84 \\
\hline 15 & Accidental, instantaneous death & 34 & $\mathbf{M}$ & - & $16 \cdot 0$ & 45 & 88 \\
\hline 18 & Chronic nephritis, uraemia & 19 & $\mathbf{M}$ & 10 & $15 \cdot 5$ & 80 & 106 \\
\hline 19 & Cerebral haemorrhage & 73 & $\mathbf{M}$ & 6 & $12 \cdot 5$ & 30 & 82 \\
\hline \multirow[t]{2}{*}{27} & Carcinoma of pancreas, biliary cir rhosis & 51 & $\mathbf{M}$ & 6 & $13 \cdot 5$ & 80 & 87 \\
\hline & Average & 50 & & & $13 \cdot 5$ & 51 & 88 \\
\hline
\end{tabular}

ribonucleic acid. Other features noted included variation in nuclear size and mitotic activity, tubule formation by groups of cells, patchy necrosis, and areas of capillary congestion. However, these did not conform to any distinct pattern and are not described.

\section{DISCUSSION}

Although over the last 65 years the actions of the sex hormones and their influence on the skeleton have gradually been disclosed, the discovery that normal adrenal cortical function is necessary for bone growth is more recent. The occurrence of osteoporosis in Cushing's syndrome had been known for some years (Eisenhardt and Thompson, 1939) when, in 1943, Albright attributed the bone changes to the 'anti-anabolic' action of one of the adrenal cortical hormones, seven years before cortisone was actually isolated. In 1949, Ingle and Prestrud demonstrated that adrenal cortical hormone is necessary for normal growth, and Pearson (1956) stated that bone repair cannot proceed in the absence of cortisone. However, despite the great amount of more recent experimental work, the role of the adrenal cortex in senile osteoporosis is still not understood.

Albright (1947) suggested that there may occur in both sexes an 'adrenopause', i.e., an involution of adrenal cortical function, similar to that undergone by the ovaries at the menopause, which, he thought, might be responsible for the osteoporosis of senility. Alternatively, he stated that, as in Cushing's syndrome, anything which led to the adrenals producing an excessive amount of glycogenic hormone over that of anabolic steroid hormones would cause osteoporosis.

The possibility that an 'adrenopause' might cause senile osteoporosis has never been disproved, and indeed Urist (1960a) described bilateral adrenal atrophy in an elderly female osteoporotic subject, although curiously enough the glands were differently affected, i.e., the zona fasciculata of one gland and the zona glomerulosa and the zona reticularis of the other were the regions stated to be atrophied. Urist and Deutsch (1960) described general atrophy of the adrenal cortex in the osteoporosis which affects white Leghorn roosters and although the similarity between this condition and senile osteoporosis appears tenuous, Urist (1960b) considered it sufficient to suggest that results of experimental therapy in hen osteoporosis might also be applicable to the human condition. It is therefore appropriate that the adrenal glands in human cases of senile osteoporosis should be studied. 
The distribution of cytoplasmic ribonucleic acid granules in adrenal cortical cells has been investigated by Symington, Duguid, and Davidson (1956) and by Symington and Davidson (1956). These authors stated that in healthy subjects ribonucleic acid is normally present only in the cytoplasm of cells in the zona glomerulosa and the zona reticularis, but that as a result of stress or the administration of A.C.T.H., the clear, lipoid-containing cells of the zona fasciculata become devoid of lipoid and compact in appearance, with an intensely eosinophilic cytoplasm rich in ribonucleic acid. This results in merging of the zona fasciculata with the underlying zona reticularis. Symington (1959) further stated that such alterations in the morphology and histochemistry of the cells of the zona fasciculata are associated with an increase in $11 \beta$ hydroxylation, and an increased gland output of cortisol. The significance of such changes could, he stated, only be appreciated in the light of corticosteroid biosynthesis, but he warned against mistaking a lipoiddepleted gland, which had ceased its period of hyperfunction, for a highly active gland. Currie and Symington (1955) also warned against mistaking lipoid reversal (Fig. 3) in the adrenal cortex for increased cortical activity. Of the two groups contrasted here the latter change was not regarded as an important source of error, for it was present in only one case and that in the control group (Case 2).

In the light of these observations it will be evident that the greater weight of the glands and the relatively greater ribonucleic acid content of those in the osteoporotic group are not in keeping with the 'adrenopause' theory. The results in fact indicate greater adrenal cortical activity in the osteoporotic group than in the control group, but this may be largely due to the longer duration of the stress period in the former group.

Unfortunately the methods employed in this investigation do not distinguish which groups of hormones were being produced, but if, for example, glucocorticoids alone were being produced in excess, then the possibility that this caused the osteoporosis cannot be excluded. It appears improbable in such an event that the total cortical hyperfunction could have been the result of stress due to the final illness because in the osteoporotic cases the vertebral bodies had lost between 30 and $50 \%$ of their calcium content. In four of the eight cases the duration of the stress period was less than 11 days, and in no case was it greater than $\mathbf{3 0}$ days. Because the average normal male adult skeleton contains about $1,750 \mathrm{~g}$. of calcium (Howard, 1950) and many of the other bones of the skeleton in addition to the spinal bones were no doubt also affected, to a lesser degree in the osteoporotic cases, such a loss would indicate an excretion of abou $600 \mathrm{~g}$. of calcium at an unprecedentedly rapid rate: Certainly the necropsy examinations did not revea evidence of excessive calcium excretion, e.g., rend calcinosis or calculi nor were there clinical mane festations to suggest prolonged increased production of adrenal glucocorticoids in any of the osteoporotio cases.

Having established that there was no morphơ? logical or histochemical evidence to support the theory of an 'adrenopause' in the osteoporotic cases. the position of adrenal sex hormone production anf its possible role in the aetiology of senile osteo. porosis requires consideration.

There is now abundant experimental evidence tha $\vec{F}$ oestrogens play a major role in the bone formatio of birds and mammals and that androgens inhib黑 this action (Suzuki, 1958). Furthermore, personad experiments (1962) have demonstrated that oestrogens will restore normal bone density in osteoporosis caused by gonadal sex hormone deficiency in male rats, and that androgens not only were ineffective but actually inhibited the osteogenic effect. Since the human adrenal cortex produces only very small amounts of oestrogenic substances, unless there is $\$$ specific lesion such as an adenoma (Symingtons 1959), it appears unlikely that imbalance betwee adrenal glycogenic and adrenal anabolic steroid was the cause of the osteoporosis in the present series of cases. It is more probable that the osteoe porosis in these cases was due to gonadal sex hormone (oestrogen) deficiency.

I am indebted to Mrs. Stella Loomes for technic assistance.

\section{REFERENCES}

Albright, F. (1943). Harvey Lect., 1942-1943, 38, 123.

(1947). Ann. intern. Med., 27, 861.

Beck, J. S., and Nordin, B. E. C. (1960). J. Path. Bact., 80, 391

Brachet, J. (1953). Quart. J. micr. Sci., 94, 1.

Caldwell, R. A. (1962). Brit. J. exp. Path., 43, 103.

- and Collins, D. H. (1961). J. Bone Jt Surg., 43B, 346.

Carr, I. (1959). J. Path. Bact., 78, 533.

Currie, A. R., and Symington, T. (1955). Proc. roy. Soc. Med., 480 908.

Eisenhardt, L., and Thompson, K. W. (1939). Yale J. Biol. Med., 1 응 507.

Howard, R. P. (1950). Canad. med. Ass. J., 63, 258.

Ingle, D. J. (1953). Amer. Practit., n.s. 4, 628.

-

Pearson, O. H. (19S6). In 'Hormones and the Aging Process', T. Engle and G. Pincus, p. 147. Academic Press, New Yorkळ

Symington, T. (1959). In 'Modern Trends in Pathology', edited bf D. H. Collins, p. 248. Butterworth, London. , and Davidson, J. N. (1956). Scot. med. J., 1, 15.

_ 580.

Suzuki, H. K. (1958). J. Bone Jt Surg., 40A, 435.

Urist, M. R. (1960a). In 'Bone as a Tissue,' edited by K. Rodah Nicholson, J. T., and Brown, E. M., p. 18. McGraw-Hill New York.

(1960b). Endocrinology, 67, 879.

__, and Deutsch, N. M. (1960). Ibid., 66, 377. 